\title{
A sex-linked locus (Mpi) in the opossum shrimp Mysis relicta: implications for early postglacial colonization history
}

\author{
RISTO VÄINÖLÄ \\ Finnish Museum of Natural History, PO Box 17, FIN-00014 University of Helsinki, Finland
}

\begin{abstract}
Strong and persistent associations between sex and genotype frequencies at the Mpi allozyme locus (mannose-6-phosphate isomerase) were found in three lacustrine populations of Mysis relicta sp. I in eastern Finland. Almost all females were homozygotes 100/100, whereas most males were heterozygotes 107/100. This disequilibrium suggests a complete linkage between Mpi and a sex-determining factor in a male heterogametic system and provides the first evidence for a genetic sex-determining mechanism in the crustacean order Mysida. However, no disequilibria were found in other parts of the species range. Potential mechanisms involved in generating the disequilibria are considered (sex-specific selection, recombination modifiers, hitchhiking, population bottlenecks). The restricted geographical distribution of the sex-Mpi association can be related to the early postglacial geological evolution of the lakes studied. A detailed scenario for the colonization history and genetic changes in the populations is presented. This involves initial immigration using temporary connections among ice-marginal lakes in eastern Finland approximately $10000 \mathrm{BP}$, associated population bottlenecks, and the origin and local selective spread of a nonrecombining Y-Mpi ${ }^{107}$ chromosome in the Sotkamo area $c .9300 \mathrm{BP}$. Soon after the isolation of the three headwater lakes (c. $9100 \mathrm{BP}$ ), a new recombination modifier caused a breakdown of the association in populations downstream.
\end{abstract}

Keywords: allozymes, linkage disequilibrium, Mysida, population history, sex determination, sex linkage.

\section{Introduction}

One of the principal approaches to identifying the mode of sex determination is through tracing the segregation of sex-linked genes in pedigree data (e.g. Bull, 1983). In many organisms, this is precluded by the difficulty of rearing offspring to an age at which they can be sexed. However, a persistently unbalanced distribution of marker genotypes or phenotypes in the two sexes at the population level may per se provide evidence of linkage disequilibrium with, and physical linkage to, a sex-determining factor, if the genetic background and expression of the marker trait can be taken to be well established. This is usually the case for allozymes. Population data can then also give a clue to the sex-determining mechanism, whether male (XY) or female $(\mathrm{ZW})$ heterogametic.

Correspondence. E-mail: risto.vainola@helsinki.fi
From earlier studies of sex linkage in crustaceans, both male and female heterogamety have been inferred; sex-linked genes are known from branchiopods, ostracods, isopods and decapods (Shaklee, 1983; Legrand et al., 1987; Havel et al., 1990; Siegismund \& Christensen, 1992). From evidence other than sex linkage, the diversity of crustacean sex-determining mechanisms is wide, including various heterogametic systems, oligo- and polygenic mechanisms, sequential hermaphroditism and environmental or cytoplasmic control (GingsburgerVogel \& Charniaux-Cotton, 1982; Legrand et al., 1987). However, no previous data, cytogenetical or other, exist on sex determination in the order Mysida.

In this paper, population data on a sex-linked allozyme locus in the opossum shrimp Mysis relicta sp. I are presented. This provides the first evidence for a genetic sex-determining mechanism in mysidan crustaceans. An association (linkage disequilibrium) 
between the marker and sex loci was encountered in three populations in a geographically limited area in eastern Finland. Using information on the early Holocene geological evolution of lakes and on current gene frequency variation, the origin and spread of the association can be accurately dated and related to the colonization history of lakes during the deglaciation of Fennoscandia.

\section{Materials and methods}

The Mysis relicta species group comprises lacustrine and brackish water mysid shrimps with a circumpolar distribution in the previously glaciated northern regions; four sibling species are currently recognized (Väinölä, 1986; Väinölä et al., 1994). Mysis relicta sp. I, dealt with here, lives in lakes draining to the Baltic Sea and in the coastal and peripheral parts of the Baltic Sea itself. The material comes from a geographical survey of genetic differentiation throughout northern Europe, involving 114 populations and seven allozyme loci. The main results in this paper are from three lakes in eastern Finland: Lake Jormasjärvi and Lake Ontojärvi in the Oulujoki drainage basin, which discharges west to the Bothnian Bay, and Lake Keyritty in the Vuoksi river basin draining south through Lake Ladoga (Fig. 1).

The population in Lake Jormasjärvi was sampled in three consecutive years, in July 1985, August 1986 and July 1987, using a beam trawl in the deepest part of the lake $(27 \mathrm{~m})$. The population consisted of two discrete cohorts. The older cohort $(1+$ years old; mean length $\pm \mathrm{SD}=16.5 \pm 0.8 \mathrm{~mm}$ in 1987) was exclusively female, whereas both sexes were equally represented in juveniles $(0+)$ born the same year $(8.0 \pm 0.6 \mathrm{~mm})$. A similar size and sex distribution was found in most other populations studied, particularly in central Finland. [Mating in Mysis takes place in late autumn and the release of young in early spring. The lack of adult $(1+)$ males probably reflects the fact that males die soon after first mating; whether the adult females sampled had already reproduced once, and generally whether

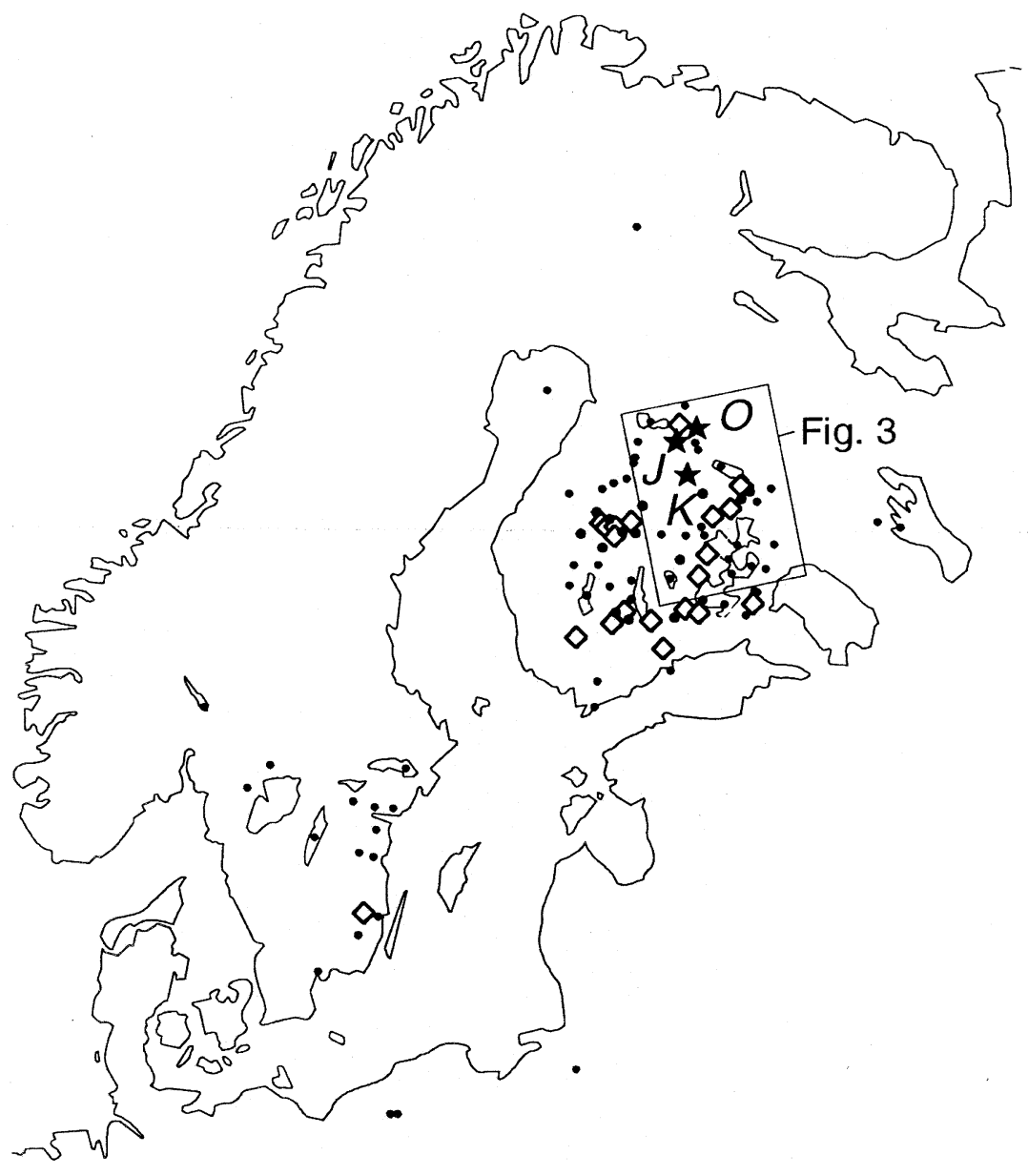

Fig. 1 Distribution of the studied Mysis relicta sp. I populations in Fennoscandia and Poland. Stars indicate the three lakes where a sex-Mpi association was observed: $J$, Jormasjärvi; $O$, Ontojärvi; $K$, Keyritty (detailed map in Fig. 3). Diamonds are lakes from which sexed juvenile samples were examined; dots indicate other populations studied.

(C) The Genetical Society of Great Britain, Heredity, 81, 621-629. 
females do reproduce twice in this lake, remains unclear.]

Sex was scored before genotyping in parts of the Jormasjärvi material (1986 and 1987) and in 20 other Fennoscandian populations (Fig. 1). In the remaining material, only the two cohorts were discriminated initially when marker genotypes were determined. Sex association in these previously genotyped samples was examined indirectly from an analysis of inter- and intracohort genotypic distributions (see Results).

Allozyme variation at the $\mathrm{Mpi}$ locus, encoding mannose-6-phosphate isomerase (EC 5.3.1.8), was detected with starch gel electrophoresis (Väinölä, 1992). In most populations, $M p i$ is polymorphic with two frequent alleles, 100 and 107 (mean frequencies 0.76 and 0.24 in 114 studied populations). There are no direct data on the inheritance of MPI allozymes in Mysis, but the genetics and co-dominant expression of this enzyme have been documented in progeny studies in several other taxa, including crustaceans (Shaklee, 1983; Siegismund, 1985; McDonald, 1989). Additional loci analysed in the populations were Aco-2, Est-3, Got-2, Mdh-2, Pgm and Tpi.

\section{Results}

\section{The J ormasjärvi population}

In the sexed material from Lake Jormasjärvi (1986, 1987), females of both cohorts were almost exclusively $100 / 100$ homozygotes at $\mathrm{Mpi}$, whereas practically all males (juveniles only) were 107/100 heterozygotes (Table 1). Also, in the previously genotyped nonsexed material (1985 and 1986), nearly all the adults (presumably females) were homozygotes, whereas juveniles had intermediate genotype and allele frequencies. Compared with Hardy-Weinberg expectations, these nonsexed juveniles showed marked heterozygote excess (i.e. deficiency of 107/107 homozygotes), as expected in a mixture of the observed male and female distributions.

$M p i^{107}$ was thus almost confined to the male sex in this population, and practically all males possessed the allele. The simplest hypothesis to account for the observed distribution is that the $M p i$ alleles are linked to, and in a nearly complete linkage disequilibrium with, a factor responsible for sex determination in a male heterogametic (XY) system: allele 107 marks the $\mathrm{Y}$ chromosome, whereas 100 is almost exclusively on $\mathrm{X}$. Assuming that the sex ratios of the nonsexed cohorts were similar to those in the sexed ones (Table 1), the data illustrate a persistence of the strong $100-\mathrm{X}$ association in four successive cohorts (born in 1984-87) and of the (almost) exclusive 107-Y association in three. This suggests that there is no significant recombination between $\mathrm{Mpi}$ and the sex factor on Y. The single 100/100 genotype in the male data could result from mis-scoring of sex, but the occasional presence of 107 on $\mathrm{X}$ is confirmed by the observation of a 107/107 individual in the nonsexed material.

\section{Other populations}

Three approaches were taken to screen for similar evidence of sex linkage in other populations. First, samples of another 20 populations were sexed and examined directly for $M p i$ frequency differences (Fig. 1). Secondly, in previously genotyped, nonsexed material, differences between adult (predominantly female) and juvenile (mixed) cohorts were examined in 32 samples with $N_{\text {juv }} \geq 40$. Thirdly, genotypical distributions were examined in previously genotyped samples that consisted mainly or exclusively of juveniles, and in the pooled material. The rationale for this approach is that an allele frequency difference between sexes will always cause an apparent heterozygote excess $(F<0)$ in the composite population. With a gene frequency difference $\Delta=p_{\mathrm{Y}}-p_{\mathrm{X}}$ between the $\mathrm{Y}$ and $\mathrm{X}$ chromosomes (or $d=\Delta / 2$ between the two sexes), the relative deviation from the Hardy-Weinberg heterozygote frequency, in a population with an equal sex ratio and overall gene frequency $p=\left(3 p_{\mathrm{X}}+p_{\mathrm{Y}}\right) / 4$, will be

$F=-\Delta^{2} /(16 p(1-p))=-d^{2} /(4 p(1-p))$

(see Fig. 2). If the sample sex ratio is biased, $m$ being the proportion of males (heterogametic sex), the apparent deviation is

$F=-m^{2} \Delta^{2} /(4 p(1-p))=-m^{2} d^{2} /(p(1-p))$,

where $p$ is the sample gene frequency. Thus, for a female-biased sample, the predicted deviation is smaller.

A strong sex-Mpi association was found in two further populations. In Lake Ontojärvi, adults were again almost entirely 100/100, whereas juveniles involved equally frequent $100 / 100$ and $107 / 100$, with only occasional 107/107 homozygotes (Table 1). This amounts to an apparent $30 \%$ heterozygote excess in juveniles $(F=-0.30)$. A similar excess was found in Lake Keyritty juveniles $\left(F=-0.35, \quad \chi_{1}^{2}=15.1\right.$, $P<0.001)$; the sex-related $M p i$ distribution in this 
lake was confirmed in an analysis of 36 additional sexed individuals. Under the model, the 107 allele frequencies on $\mathrm{X}$, estimated from adults and juvenile females, are 0.04 and 0.05 in Ontojärvi and Keyritty, respectively. On Y, 107 appears to be fixed in both populations, whether estimated from the males (Keyritty) or from the composite juvenile populations assuming a 1:1 sex ratio (both lakes).

In the remaining sexed populations, allele and genotype frequencies were generally similar in the sexes. As an example, data from Lake Kermajärvi are shown in Table 1. The combined test statistic from the 20 within-population allele frequency comparisons was $\chi_{20}^{2}=21.6 \quad(\mathrm{NS} ; \quad$ average $N=115 /$ population).
Comparisons between adult and juvenile cohorts did not reveal further associations either, apart from those discussed above. From 32 within-population comparisons, the combined $\chi_{32}^{2}=37.6$ (NS; average $N=126 /$ population). A clear difference was found in a single sample, Lake Lummenne $\left(\chi_{1}^{2}=13.0\right.$, $P<0.001) . p_{107}$ was higher in adults in this lake, and the genotype frequencies (20:7:3 in adults; 68:8:0 in juveniles), with a heterozygote deficit in adults, cannot be explained by a difference between sex chromosomes.

The third approach, assessing genotype distributions in composite samples, should readily disclose nearly complete disequilibria similar to those above $(\Delta>0.95, F<-0.25)$; the power to detect smaller $\Delta \mathrm{s}$

Table 1 Mpi genotype and allele frequencies in partitions of Mysis relicta sp. I samples from the Lakes Jormasjärvi, Keyritty, Ontojärvi and Kermajärvi

\begin{tabular}{|c|c|c|c|c|c|c|c|}
\hline \multirow[b]{2}{*}{ Cohort } & \multirow[b]{2}{*}{ Sex $\dagger$} & \multirow[b]{2}{*}{ Year } & \multicolumn{3}{|c|}{ Genotype } & \multirow[b]{2}{*}{$p_{107}$} & \multirow[b]{2}{*}{$F \ddagger$} \\
\hline & & & $100 / 100$ & 107/100 & $107 / 107$ & & \\
\hline \multicolumn{8}{|c|}{ Lake Jormasjärvi } \\
\hline Adult & (ND) & 1985 & 58 & 1 & - & 0.01 & \\
\hline Adult & (ND) & 1986 & 14 & - & - & 0 & \\
\hline Adult & $\mathrm{f}$ & 1987 & 45 & - & - & 0 & \\
\hline Juvenile & $\mathrm{f}$ & 1986 & 39 & - & - & 0 & \multirow{4}{*}{-0.34} \\
\hline Juvenile & $\mathrm{f}$ & 1987 & 46 & 1 & - & 0.01 & \\
\hline Juvenile & $\mathrm{m}$ & 1986 & 1 & 35 & - & 0.49 & \\
\hline Juvenile & $\mathrm{m}$ & 1987 & - & 52 & - & 0.50 & \\
\hline Juvenile & ND & 1985 & 43 & 31 & - & 0.21 & -0.27 \\
\hline Juvenile & ND & 1986 & 57 & 50 & 1 & 0.24 & -0.27 \\
\hline \multicolumn{8}{|c|}{ Lake Keyritty } \\
\hline Adult & $\mathrm{f}$ & 1986 & 3 & - & - & 0 & \multirow{3}{*}{-0.09} \\
\hline Juvenile & $\mathrm{f}$ & 1986 & 14 & 2 & - & 0.06 & \\
\hline Juvenile & $\mathrm{m}$ & 1986 & - & 14 & 3 & 0.58 & \\
\hline Juvenile & ND & 1986 & 48 & 72 & 3 & 0.31 & -0.35 \\
\hline \multicolumn{8}{|c|}{ Lake Ontojärvi } \\
\hline Adult & $\mathrm{f}$ & 1990 & 25 & 3 & -7 & \multirow{2}{*}{\multicolumn{2}{|c|}{0.04}} \\
\hline Adult & (ND) & 1990 & 23 & 1 & $-\}$ & & \\
\hline Juvenile & ND & 1990 & 22 & 26 & 1 & 0.29 & -0.30 \\
\hline \multicolumn{8}{|c|}{ Lake Kermajärvi } \\
\hline Adult & $\mathrm{f}$ & 1987 & 34 & 14 & 2 & 0.18 & \\
\hline Juvenile & $\mathrm{f}$ & 1987 & 44 & 27 & 3 & 0.22 & \multirow{2}{*}{+0.04} \\
\hline Juvenile & $\mathrm{m}$ & 1987 & 39 & 15 & 4 & 0.20 & \\
\hline
\end{tabular}

Some samples include both sexed and nonsexed individuals, treated separately here.

$\dagger$, female; m, male; ND, sex not determined (all adult individuals are probably female, however).

$\ddagger$ The apparent heterozygote excess $(-F)$ in a nonsexed or composite population sample. 


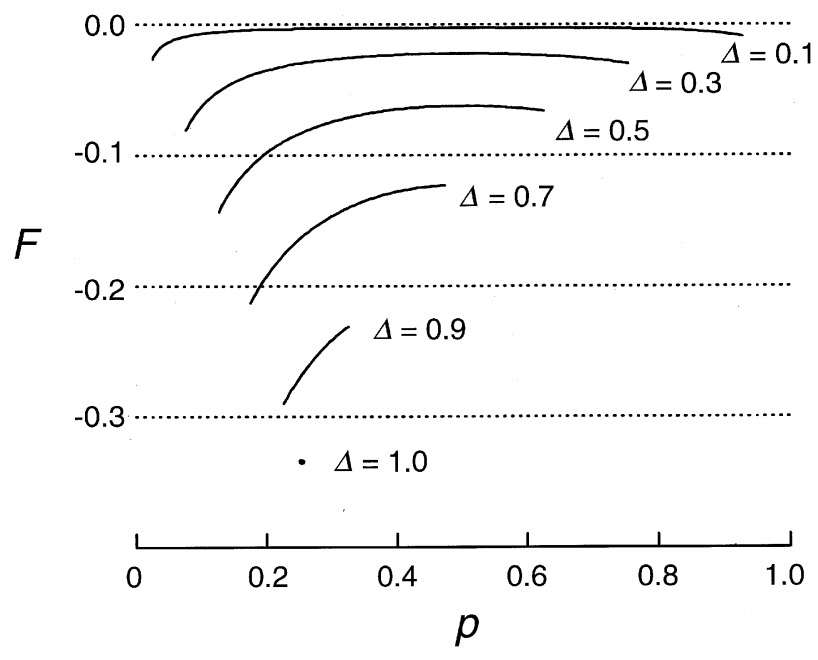

Fig. 2 Apparent relative heterozygote deviation $F$ caused by a gene frequency difference between the sex chromosomes in a panmictic population (negative $F$ indicates heterozygote excess). $F$ is plotted as a function of the total gene frequency in a 1:1 sex ratio population,

$p=\left(3 p_{\mathrm{X}}+p_{\mathrm{Y}}\right) / 4$, for various levels of gene frequency differences between chromosomes, $\Delta=p_{\mathrm{Y}}-p_{\mathrm{X}}$ (only cases $\Delta>0$ are shown; the corresponding frequency difference between sexes is $d=\Delta / 2$ ).

is much weaker (Fig. 2). Given the relationship between the conventional Hardy-Weinberg test statistic and the heterozygote deviation $F, \chi_{1}^{2}=F^{2} N$, only an estimated excess of $F=-0.18$ would be noted as significant $(P<0.05)$ with a typical sample size $N=120$; an excess this great can be realized if $\Delta>0.60$ in a $1: 1$ sample (Fig. 2). Besides the Lake Keyritty sample $(F=-0.35)$, additional sexed material was genotyped from nine lakes in which the estimated excess was $F<-0.10$ at first examination. No further allele frequency differences could be confirmed. The overall genotypical structure in a total of 99 populations with $p_{107}$ between 0.10 and 0.47 showed a slight average within-population heterozygote deficit, $F_{\text {IS }}=+0.012 \quad\left(N_{\text {TOT }}=12684\right.$; the three populations with disequilibria excluded). These data thus gave no evidence of a more general occurrence of sex-specific allele frequency differences at Mpi.

\section{Discussion}

\section{Comparative sex linkage}

The postulated sex chromosome pair in Mysis would bear homologous genes on both chromosomes. This is also the case with a number of sex-linked loci in other crustaceans, including an eye colour gene in Artemia (Bowen, 1963), colour morph genes in two isopods (e.g. Legrand et al., 1987) and decapod and isopod allozyme loci (Shaklee, 1983; Siegismund \& Christensen, 1992). Sex-linked allozymes expressed similarly on both chromosomes are also known from other taxa, including vertebrates (e.g. Allendorf et al., 1994). This pattern of homology is considered typical of a primitive stage in sex chromosome evolution (Bull, 1983).

Recombination between the marker genes and sex factor is common in such instances, allele frequencies in the sexes being similar. Yet, cases in which marker alleles are differentially associated with sex, suggesting recombination suppression, are also known: from amphibians (Ferrier et al., 1983), reptiles (Salvido et al., 1990), insects (Berlocher, 1984; Santos \& Luykx, 1985) and two crustaceans (Shaklee, 1983; Siegismund \& Christensen, 1992). In all these instances, the heterochromosome (Y or W) is fixed for one of the marker alleles - as in Mysis. Notably, both in the Hawaiian spiny lobster Panulirus marginatus (XY; Shaklee, 1983) and in the common lizard Lacerta vivipara $\left(\mathrm{Z}_{1} \mathrm{Z}_{2} \mathrm{~W}\right.$; Salvido et al., 1990), the sex-associated locus is Mpi. Mpi is also sex-linked, but X-limited, in several ostracod crustaceans (Havel et al., 1990).

There are thus two contrasting pieces of comparative evidence for the sex-Mpi association in the three Mysis populations: similar associations in distant taxa, but no association in other conspecific populations, even in neighbouring lakes. An evolutionary conservation of linkage even since the divergence of decapod and mysid lineages is improbable, in view of their age ( $>200 \mathrm{Myr}$ ) and the high chromosome numbers in both groups $(n>50$; Lécher etal., 1995). The variability of the sex-determining mechanism itself excludes such conservation; the heterogametic sex can even vary within crustacean species (Gingsburger-Vogel \& Charniaux-Cotton, 1982).

From the restricted geographical distribution, it then seems most likely that the disequilibrium actually arose postglacially in the particular populations or in their common ancestral population, in isolation from the remaining Fennoscandian Mysis relicta sp. I. In each of the three lakes, the 107-Y chromosome appears to be fixed. The absence of recombination between $\mathrm{X}$ and $\mathrm{Y}$ is demonstrated by the persistence of disequilibrium in Lake Jormasjärvi over four generations; most probably, it has been retained for thousands of years (see below). On the other hand, nothing can be said of recombination between $\mathrm{X}$ chromosomes. 
Palaeohydrography and population history: dating genetic changes

Because of the biological characteristics of Mysis and the information available on its population history, there is an unusual opportunity to consider the circumstances under which the association originated and spread, and the genetic and evolutionary factors involved. Mysis is unable to disperse upstream, either actively or passively (Segerstråle, 1976). Therefore, the isolation of a lake from downstream populations, for instance by isostatic land uplift, can be equated with unidirectional cessation of gene flow. This is useful, because there is a detailed record of the postglacial geological evolu- tion of the Finnish lake network (Saarnisto, 1971; Eronen, 1983). Data on the overall geographical variation at $M p i$ and six other loci of $M$. relicta $\mathrm{sp.} \mathrm{I}$ give further clues to the population history (R. Väinölä, in prep.). From a joint consideration of the geographical, geological and genetic data (Fig. 3), an accurately dated model for the history of the sex-Mpi association and the populations involved can be constructed. This is presented below as a series of seven successive stages. The genetic mechanisms that could have generated the disequilibria are then considered separately.

1 With the ice retreat, $M$. relicta $\mathrm{sp}$. I initially colonized Finland from the south-east (Ladoga direction)

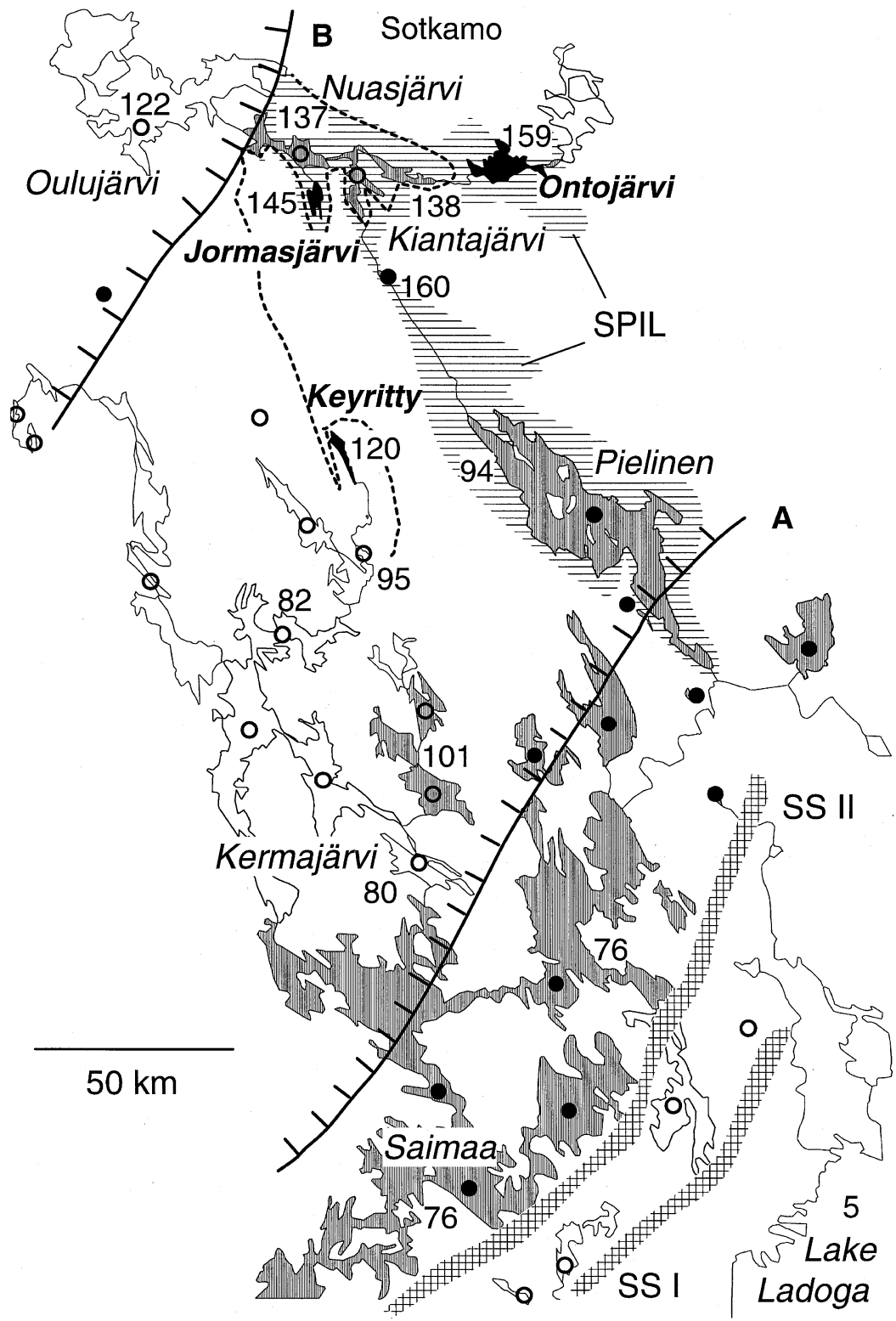

Fig. 3 The location of lakes with sex-Mpi associations in eastern Finland (black), in relation to palaeohydrography during the deglaciation (Saarnisto, 1971; Kemiläinen, 1986; Miettinen, 1996), and genetic characteristics of Mysis relicta sp. I populations (see text for explanation). A: glacier margin at the Saimaa Ice Lake stage $c .10000$ вP. Shading: lakes now inhabited by the genetic population type $\mathrm{E}$, postulated to have arisen in the Saimaa Ice Lake (technically, the E-type is defined by a cutpoint dividing the first principal axis of six-locus allele frequency data). Horizontal hatching: the Sotkamo-Pielinen Ice Lake, SPIL, c. 9300 вP. B: glacier margin at the final stage of SPIL. Interrupted line: eastern shore of the Baltic immediately after the collapse of SPIL. Black dots: Mysis populations with low $\mathrm{Mpi}^{107}$ frequencies, $p<0.12$. Circles: populations with high frequencies $p>0.15$ (data for the black lakes are in Table 1). SSI, SSII: Salpausselkä marginal ridges. The figures indicate recent water levels (m a.s.l.); during the deglaciation, the ground was tilted $0.5-0.6 \mathrm{~m} \mathrm{~km}^{-1}$ to the north-west as a result of isostatic depression. 
in Baltic Ice Lake waters, $>10000$ BP. The invading stock had a relatively high $\mathrm{Mpi}^{107}$ frequency $(p>0.30)$, as evidenced by data from populations isolated at that time (between the SSI and SSII marginal ridges, Fig. 3), and from the Baltic Sea itself.

2 At c. $10000 \mathrm{BP}$, a local Saimaa Ice Lake was isolated between the SSII ridge and the ice margin in south-east Finland (line A in Fig. 3; Saarnisto, 1971). The current populations descending from that lake have low $M p i^{107}$ frequencies $(p=0-0.12)$ and further common features in their multilocus genetic structure, e.g. generally low heterozygosity. This peculiar genetic composition - the E-type - probably resulted from a population bottleneck at that time (R. Väinölä, in prep.; hatched lakes and dots in Fig. 3).

3 From Saimaa, Mysis spread north using temporary connections between ice-marginal lakes. A connection to the emerging Pielinen basin was broken by land uplift c. $9800 \mathrm{BP}$ (Miettinen, 1996). Pielinen then merged with ice lakes further north, resulting in the Sotkamo-Pielinen Ice Lake, SPIL. This brought Mysis over the present watershed to the Ontojärvi and Jormasjärvi basins, then encompassed by SPIL.

4 The SPIL collapsed c. $9300 \mathrm{BP}$, when ice withdrew from a low threshold north-west of Lake Jormasjärvi (line B in Fig. 3). Waters in the north-westerly parts of SPIL were drained by approximately $30 \mathrm{~m}$ to be confluent with the Baltic level (dashed shoreline). At the same time, the easterly parts, including Ontojärvi and Pielinen, were left isolated as independent lakes (Kemiläinen, 1986; Saarelainen \& Vanne, 1997): any further gene flow between or into these two lakes thus ceased. From this history, the actual origin of the $107-\mathrm{Y}$ association can be traced to Lake Ontojärvi. If the nonrecombining 107-Y chromosome was fixed because of a selective advantage, as argued below, it should have spread to wherever it had access. Mysis in Lake Pielinen and in adjoining lakes of similar age still have low $\mathrm{Mpi}^{107}$ frequencies and show no evidence of sex linkage. By contrast, the Ontojärvi population shows a complete $107-\mathrm{Y}$ association, and consequently $p_{107} \geq 0.25$ (Table 1). Thus, the association evidently arose and was fixed in Ontojärvi only after connections with Pielinen were broken. Note that on X, the Ontojärvi Mysis still retains the low 107 frequency as a SPIL heritage.

5 After the collapse of SPIL, both the Jormasjärvi and Keyritty basins were temporarily situated downstream of Lake Ontojärvi and thus accessible for a new advantageous 107-Y chromosome to invade from there. Both these basins made marginal embayments of the Baltic (Ancylus Lake phase) at that time (Fig. 3).

6 The opportunity for invasion was short-lived, however, because Jormasjärvi and Keyritty were also isolated only a couple of hundred years later as a result of isostatic uplift (Eronen, 1983; Kemiläinen, 1986). Thus, the favoured mutation event can be assigned into a 200- to 300-year interval between the isolation of Ontojärvi (SPIL drainage event) and the isolation of the other two lakes.

7 Obviously, if the 107-Y chromosome had a selective advantage, it should have colonized all waters downstream of Ontojärvi, Jormasjärvi and Keyritty. Yet, no association is found even in immediately neighbouring lakes, including Kiantajärvi, Nuasjärvi and Oulujärvi (downstream of Jormasjärvi and/or Ontojärvi) or in Ala-Siikajärvi (95 $\mathrm{m}$ a.s.l., downstream of Keyritty). The paradox may be accounted for by the introduction of another mutation $r$, which reconstituted recombination on the Y chromosome and proved superior to that fixed in the three upstream lakes. This hypothesis has support in a special anomaly in the genetic structure of the downstream populations: the multilocus genetic compositions in Lakes Kiantajärvi and Nuasjärvi indicate a SPIL ancestry (E-type); yet the populations have relatively high frequencies of $M{ }^{107}(p=0.21-0.31)$, an allele that was rare in the SPIL populations (Fig. 3). On our hypothesis, the downstream populations were actually first fixed for 107-Y, which invaded early from Lake Ontojärvi; the total 107 frequency was thus inflated selectively to 0.25 at least. The new $r$ mutation then allowed the redistribution of this frequency evenly among the $\mathrm{Y}$ and $\mathrm{X}$ chromosomes. Because Kiantajärvi and Nuasjärvi (now at 137-138 m) themselves were isolated only a few decades later than Jormasjärvi $(145 \mathrm{~m})$, the second mutation should either have arisen in this very area or, alternatively, have been introduced by gene flow from the west soon after the isolation of Jormasjärvi.

\section{Causes of disequilibria}

In the scenario above, the origin, spread and decay of the sex-Mpi association were attributed to selection. In principle, however, a disequilibrium could also arise purely by chance: a severe population bottleneck could fix different alleles on $\mathrm{X}$ and $\mathrm{Y}$, if recombination is suppressed. Recent bottlenecks have thus been suggested to account for the fixed marker-Y associations in a Rhagoletis fly (Berlocher, 1984), similar to those in Mysis. 
Traces of a local bottleneck are in fact seen in Lake Jormasjärvi, with strong allele frequency deviations from the ancestral SPIL composition at the other loci studied $\left(F_{\mathrm{ST}}=0.2\right.$; unpubl. data). There is, however, no such evidence from the other two lakes. Theoretically, a bottleneck in the male sex only could still have fixed a rare nonrecombining 107-Y chromosome while leaving no traces on autosomal loci. But as $\mathrm{Mpi}^{107}$ was especially rare in populations of a SPIL ancestry, the odds are negligible that this particular allele could have been fixed independently in three populations. On the other hand, if the origin of the association was unique (in Ontojärvi), its nonselective spread over the vast area down to Keyritty is not conceivable in the palaeohydrographical context. Chance events alone, therefore, cannot explain the distribution of the sex-Mpi association.

For a selective spread of the association, a number of scenarios are possible. They would involve various sequences of mutation at $\mathrm{Mpi}$ or a tightly linked locus; at another, antagonistic locus (i.e. a locus with alternative alleles favoured in the two sexes); and at recombination modifiers, which could include chromosomal rearrangements such as auto-Y translocations. For instance, any mutation that reduces recombination between an antagonistic locus and the sex factor would be selected for (e.g. Bull, 1983). If an antagonistic locus were present on the sex chromosomes, a new recombination suppressor on $\mathrm{Y}$ itself would cause hitch-hiking to fixation of the allele at any locus on (the suppressed region of) that chromosome. If an antagonistic locus were originally on an autosome, its translocation to the sex chromosome would be favoured (Charlesworth \& Charlesworth, 1980); this has been suggested as a major mechanism leading to sex chromosome differentiation (Bull, 1983). In an absence of recombination between the sex chromosomes ('presence of a recombination suppressor'), any advantageous (nonrecessive) mutation $m$ on the nonrecombining segment of $\mathrm{Y}$ could also draw along to fixation all the linked genes, without spreading to $\mathrm{X}$.

Any of these mechanisms could have fixed a rare $M p i^{107}$ allele on the $\mathrm{Y}$, whether $\mathrm{Mpi}$ itself was involved in the selection or not. The last one, i.e. a homogenizing selective sweep on a nonrecombining segment of the chromosome, may appear the most general, as it does not directly invoke antagonistic selection. On balance, it assumes that recombination was already suppressed on the mutating chromosome. Intraspecific genetic variation in the recombination rate of sex chromosomes is well documented in other crustaceans (Gingsburger-Vogel \& Charniaux-Cotton, 1982).
With this scenario, the final decay of the disequilibrium in the populations downstream, as postulated at stage (7) in the previous section, would also be readily understood. If the association was actually built up by a selective sweep of $m$ on a nonrecombining 107-Y chromosome, a modifier mutation $r$ that reconstituted recombination on $\mathrm{Y}$ would obviously have an indirect selective advantage, because it also enabled the spread of the advantageous $m$ to $\mathrm{X}$ and females. In that case, it may indeed be more difficult to understand why the modifier mutations have been rare enough to allow the persistence of the disequilibria for 9000 generations in three independent populations.

\section{Acknow ledgements}

I thank H. Rockas for help in the field; P. Seppä, K. Vainio, P. Tuominen and J. Vainio for laboratory assistance; P. Pamilo, D. Charlesworth, B. Charlesworth and $\mathrm{H}$. Hyvärinen for comments and discussion; and the Emil Aaltonen Foundation and the Academy of Finland for financial support.

\section{References}

Allendorf, F. W., GELlmAN, W. A. AND THOMPSON, G. H. 1994. Sex-linkage of two enzyme loci in Oncorhynchus mykiss (rainbow trout). Heredity, 72, 498-507.

BERLOCHER, S. H. 1984. Genetic changes coinciding with the colonization of California by the walnut husk fly, Rhagoletis completa. Evolution, 38, 906-918.

BOWEN, s. т. 1963. The genetics of Artemia salina. II. White eye, a sex-linked mutation. Biol. Bull., 124, $17-23$.

Bull., J. J. 1983. The Evolution of Sex Determining Mechanisms. Benjamin/Cummings Publ. Co., Menlo Park, CA.

CHARlesworth, D. AND CHARLESWORTH, B. 1980. Sex differences in fitness and selection for centric fusions between sex-chromosomes and autosomes. Genet. Res., 35, 205-214.

ERONEN, M. 1983. Late Weichselian and Holocene shore displacement in Finland. In: Smith, D. E. and Dawson, A. G. (eds) Shorelines and Isostasy, pp. 183-207. British Geogr. Spec. Publ. 26. Academic Press, London.

FERRIER, v., GASSER, F., JAYLET, A. AND CAYROL, C. 1983. A genetic study of various enzyme polymorphisms in Pleurodeles waltii (Urodele Amphibian). II. Peptidases: demonstration of sex linkage. Biochem. Genet., 21, 535-549.

GINGSBURGER-VOGEL, T. AND CHARNIAUX-COTTON, H. 1982. Sex determination. In: Abele, L. G. (ed.) The Biology of Crustacea, vol. 2, pp. 257-281. Academic Press, New York.

HAVEl, J. E., HEBERT, P. D. N. AND DELORME, L. D. 1990. Genetics of sexual Ostracoda from a low Arctic site. $J$.

(C) The Genetical Society of Great Britain, Heredity, 81, 621-629. 
Evol. Biol., 3, 65-84.

KEMILÄINEN, H. 1986. Landforms as indicators of LateGlacial processes in the area of Vuokatti hill belt, Sotkamo (In Finnish, English summary). Nordia Tiedonantoja, Ser. A, 1, 1-33.

LÉCHER, P., DEFAYE, D. AND NOËL, P. 1995. Chromosomes and nuclear DNA of Crustacea. Invertebr. Reprod. Devel., 27, 85-114.

LEGRAND, J. J., LEGRAND-HAMELIN, E. AND JUCHAULT, P. 1987. Sex determination in Crustacea. Biol. Rev., 62, 439-470.

McDONALD, J. H. 1989. Selection component analysis of the Mpi locus in the amphipod Platorchestia platensis. Heredity, 62, 243-249.

miettinen, A. 1996. Pielisen jääjärven kehityshistoria (The history of the Pielinen ice lake). Terra (Helsinki), 108, 14-19.

SAARELAINEN, J. AND VANNE, H. 1997. Sotkamon jääjärvi (Sotkamo Ice Lake). Terra (Helsinki), 109, 25-32.

SAARnisto, M. 1971. The history of Finnish lakes and Lake Ladoga. Soc. Sci. Fennica, Comment. Phys.-Mathem., 41, 371-388.

SALVIDO, S., PASTEUR, G., HEULIN, B., BÖHME, W., KURIYANOVA, L. AND GUILlaUmE, C. 1990. Natural selection and geographical variation in a known sex-linked gene of the common lizard in Europe. Implications for chromosomal evolution. Heredity, 64, 131-138.
SANTOS, O. AND LUYKX, P. 1985. Holozygosity for sex-linked genes in males of the termite Incisitermes schwarzi. Biochem. Genet., 23, 729-740.

SEgERstrÅle, s. G. 1976. Proglacial lakes and the dispersal of glacial relicts. Soc. Sci. Fennica, Comment. Biol., 83, $1-15$.

SHAKlEE, J. B. 1983. Mannosephosphate isomerase in the Hawaiian spiny lobster Panulirus marginatus: a polymorphic, sex-linked locus useful in investigating embryonic and larval sex ratios. Mar. Biol., 73, 193-201.

SIEGISMUND, H. R. 1985. Genetic studies of Gammarus. III. Inheritance of electrophoretic variants of the enzymes mannose phosphate isomerase and glucose phosphate isomerase in Gammarus oceanicus. Hereditas, 102, 25-31.

SIEGISMUND, H. R. AND CHRISTENSEN, B. 1992. A sex-linked enzyme polymorphism in the marine isopod Jaera ischiosetosa. J. Hered., 83, 388-393.

VÄINÖLÄ, R. 1986. Sibling species and phylogenetic relationships of Mysis relicta (Crustacea: Mysidacea). Ann. Zool. Fenn., 23, 207-221.

VÄINÖLÄ, R. 1992. Evolutionary genetics of marine Mysis spp. (Crustacea: Mysidacea). Mar. Biol., 114, 539-550.

VÄINÖLÄ, R., RIDDOCH, B. J., WARD, R. D. AND JONES, R. I. 1994. Genetic zoogeography of the Mysis relicta species group (Crustacea: Mysidacea) in northern Europe and North America. Can. J. Fish. Aquat. Sci., 51, 1490-1505. 